\title{
Comparison between conventional shot peening (SP) and surface mechanical attrition treatment (SMAT) on a Titanium alloy.
}

\author{
D. Gallitelli ${ }^{1, a}$, D. Retraint ${ }^{1, b}$, E. Rouhaud ${ }^{1, c}$ \\ ${ }^{1}$ Charles Delaunay Institute, LASMIS, UMR STMR CNRS 6279, University of Technology of \\ Troyes, 10000 Troyes, France \\ a donato.gallitelli@utt.fr, b delphine.retraint@utt.fr, cEmmanuelle.rouhaud@utt.fr
}

Keywords: Titanium Alloy, Shot peening, SMAT, Residual stress, Hardness, Roughness

\begin{abstract}
In this paper the residual stress states induced by conventional shot peening (SP) and surface mechanical attrition treatment (SMAT) are compared. The treated parts correspond to plates made of a titanium alloy. Different intensities of these two mechanical treatments are first considered: their influence on the surface characteristics (roughness, hardness...) is studied.

These experimental data are then used to develop a model for the residual stress profiles with dimensional analysis. Experimental and analytical approaches are then discussed.

\section{Introduction}

Surface plastic deformation processes have become extensively used by industries to produce metallic components with superior mechanical properties. Shot peening (SP) is absolutely the most popular plastic deformation process. In SP a stream of shot is blasted against the workpiece (Fig.1a), and the multiple impacts induce superficial compressive residual stress on the surface. This residual stress improves mechanical properties and fracture resistance of the treated part.

Surface mechanical attrition treatment (SMAT), in Figure 1b, is based on the same principle than $\mathrm{SP}$, the main differences are the size of shot, (between $0,25 \mathrm{~mm}$ to $1 \mathrm{~mm}$ for SP, and $1 \mathrm{~mm}$ to $8 \mathrm{~mm}$ for SMAT) and the velocity (between $20 \mathrm{~m} / \mathrm{s}$ to $150 \mathrm{~m} / \mathrm{s}$ for SP, and $3 \mathrm{~m} / \mathrm{s}$ to $20 \mathrm{~m} / \mathrm{s}$ for SMAT). Also, the shape of the elements composing the shot is not the same, these are very regular and hard spheres for SMAT. Another difference resides in the device that is used for projecting the shot. In the SMAT the shot is in a closed chamber and set in motion with the vibration of a sonotrode (the chosen frequency is here $20 \mathrm{kHz}$ ) [1].

These differences have a significant impact on surface characteristics and mechanical properties. We thus propose to analyze and quantify the consequences of both processes in the present work. An experimental and analytical study is thus proposed to evaluate and compare the induced surface characteristics and residual stress profiles.
\end{abstract}




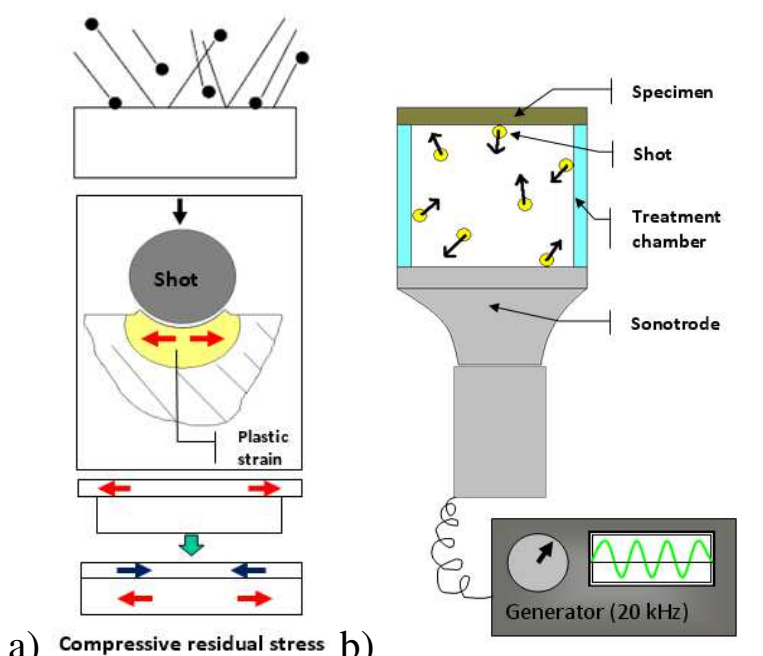

a) Compressive residual stress b)

Figure 1 a) Shot peening principle; b) SMAT principle.

\section{Titanium Alloy Ti-6Al-4V}

Titanium alloys are known for their very good mechanical properties (tab. 1), low weight ratio and corrosion resistance. They are widely used in a very large range of applications like aerospace industry, biomedical applications, marine applications, chemical industry and gas turbine. The Ti6Al-4V is based on $90 \%$ on Titanium, $6 \%$ on Aluminum and $4 \%$ on Vanadium (weight \%). The studied alloy is an $\alpha+\beta$ alloy; the $\alpha$ phase is hexagonal close packed and the $\beta$ phase is body centred cubic with grains size around $10 \mu \mathrm{m}$.

Table1 Properties of Ti-6Al-4V.

\begin{tabular}{|l|l|}
\hline Ti-6Al-4V \\
\hline Yield Strength (MPa) & 950 \\
\hline Ultimate Tensile Strength (MPa) & 1020 \\
\hline Vickers Hardness (HV) & 311 \\
\hline Modulus of Elasticity $(\mathrm{GPa})$ & 110 \\
\hline Density $\left(\mathrm{kg} / \mathrm{m}^{3}\right.$ ) & 4400 \\
\hline Poisson's ratio & 0,34 \\
\hline
\end{tabular}

\section{Treatments}

We have essentially tested two different conditions for both treatments:

- A LOW condition with Almen intensity of $15 \mathrm{~A}$ and coverage ratio of $125 \%$.

- a HIGH condition with Almen intensity of 23A and coverage ratio over $3000 \%$.

The treated specimens are circular plates with a diameter of $80 \mathrm{~mm}$. Two thicknesses have been considered according to the treatment intensity to avoid a potential bending of the plates: $6 \mathrm{~mm}$ for the low intensity conditions (15A) and $10 \mathrm{~mm}$ for the high intensity conditions (23A).

\section{Surface Quality: Roughness}

Regarding surface treatments, roughness is an important parameter because it has a significant influence on the lifespan of mechanical parts. Experimental results show an important difference between SP and SMAT concerning the roughness (Fig.2a). Conventional shot peening increases roughness more then SMAT due to the irregular shape of the shot that impact the specimen at very 
high velocity. Actually, a factor around ten between SMAT low and SP low and a factor of about seven between SMAT high and SP high was observed.

a)
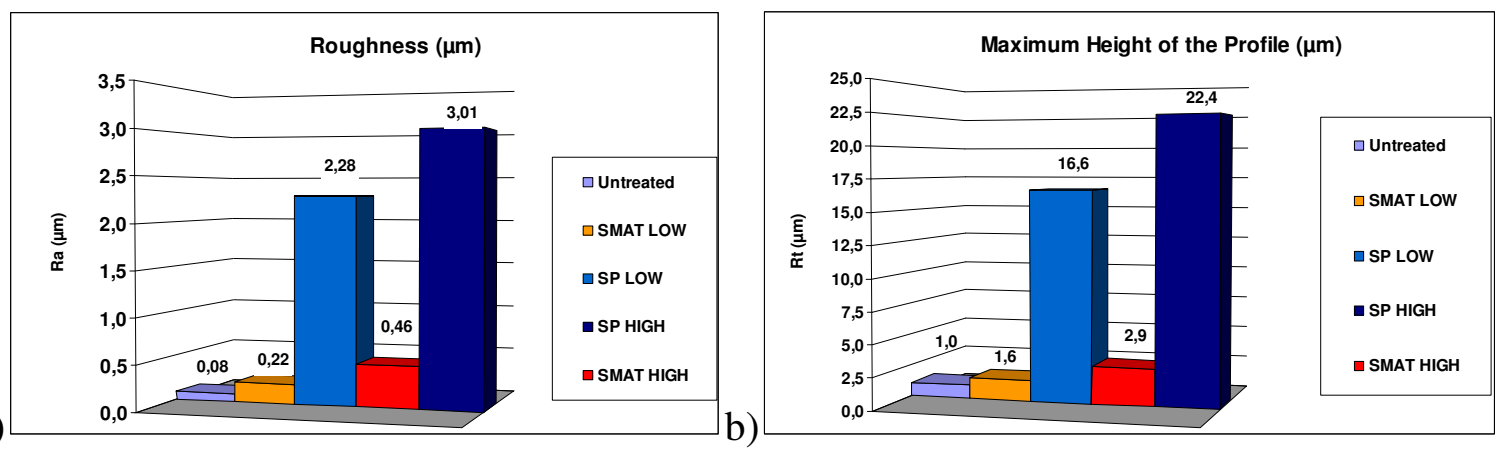

Figure 2 Comparison between SP and SMAT on Roughness (a) and height of surface profile (b)

Another important parameter that has to be taken into account when a good quality of surface is required is the height of the surface profile (Fig.2b). This is actually a measure of the thickness of the material that has to be removed to achieve a smooth surface. Looking at Figures $3 \mathrm{a}$ and $3 \mathrm{~b}$, it is evident that conventional shot peening generates an irregular surface that seems damaged. To achieve a smooth surface after conventional shot peening an intensive polishing is required.

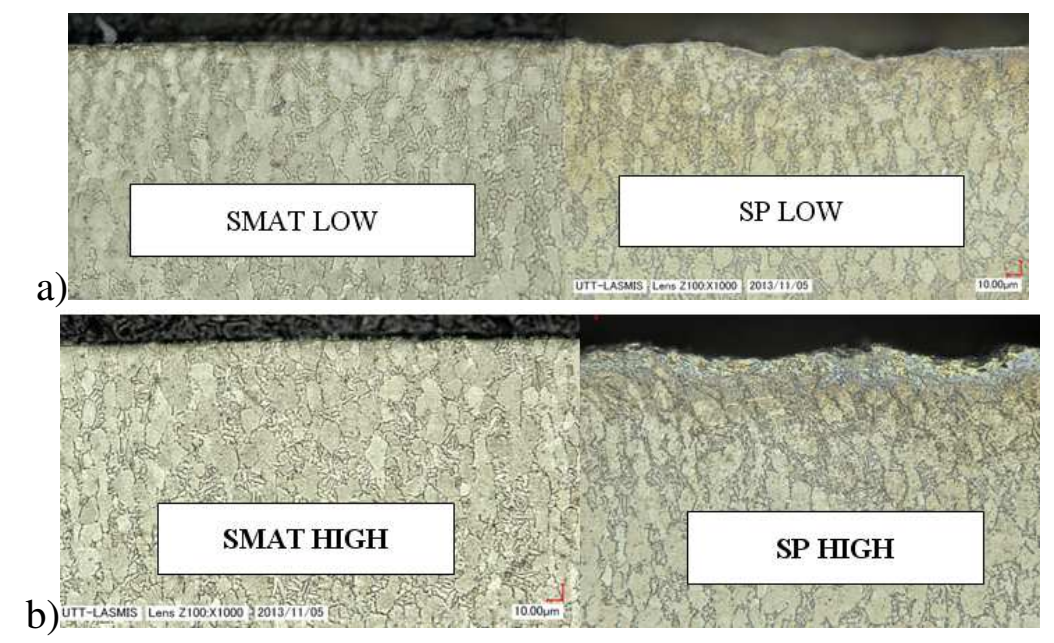

Figure 3 Cross section and microstructure for both treatments; a) LOW; b) HIGH.

\section{Hardness}

Figure 4a presents the surface Vickers micro-hardness for all specimens compared to the untreated material using $1 \mathrm{~kg}$ load. The surface hardness has increased by about $15 \%$ in every treated specimen. More interesting and accurate results are obtained on the cross-sections: Figure $4 \mathrm{~b}$ presents the micro-hardness evolution as a function of the depth beneath the surface for all the samples. 
a)
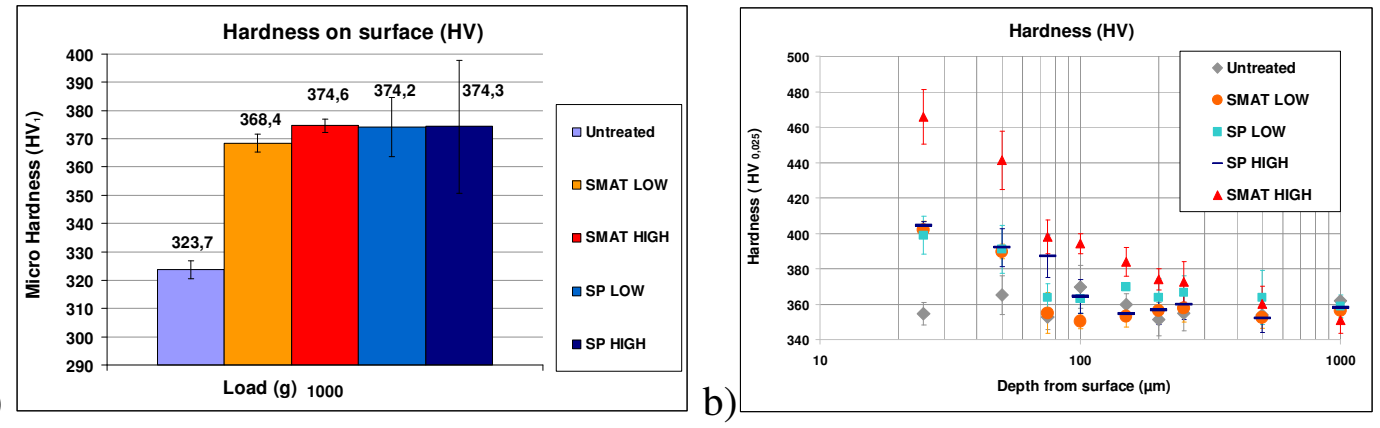

Figure 4 a) Micro-hardness on top treated surface; b) Micro-hardness as a function of depth measured on crosssection.

While no significant difference can be noticed between the different treated specimens in Fig. 4a, a remarkable increase of hardness is obtained for the part treated with SMAT with the HIGH condition as shown in Fig.4b. The micro-hardness measurements performed on the surface (Fig. 4a) affect a quite thick layer below the surface (about 80 micrometers) and present a quite huge discrepancy induced by the rough surfaces. The high micro-hardeness values reached below the surface after SMAT HIGH (Fig. 4b) could be explained by the presence of nanostructures created with the treatment. The multiple directional impacts of SMAT treatment change the size of the grains, hence generating a superficial nanostructure layer [2]. The effect of grain size on hardness is formulated in Hall-Petch relation wich reveals an inverse relationship between the hardness and grain size. It's observed that grain boundaries act as a barrier to dislocation motion: reducing the grain size will increase the volume fraction of grain boundaries and reduce the possibility of dislocation movement.

\section{Residual Stress state}

Residual stress state has been analyzed using a simple analytical model, based on dimensional analysis [3]. With the model, it is possible to plot a residual stress profile (Fig. 5a, 5b) knowing the shot peening parameters and mechanical properties of the shot and specimen. A model to calculate the velocities of the spheres during the ultrasonic shot peening is also used [4,5].

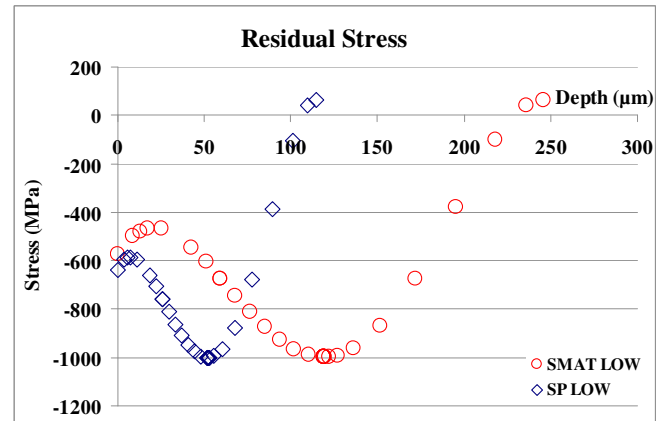

a)

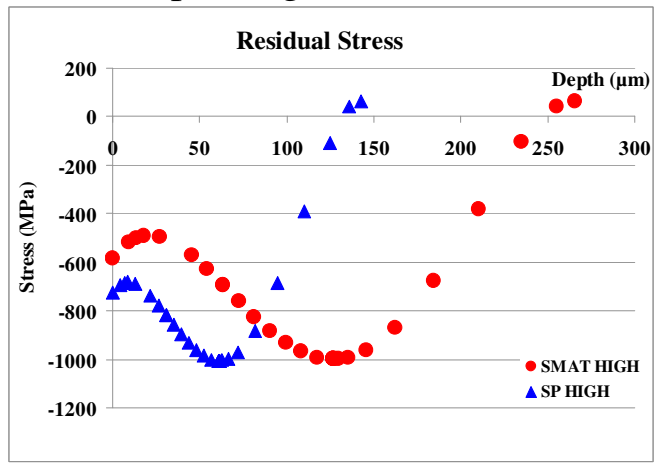

b)

With this model, it is possible to do qualitative considerations on residual stress profiles after SP or SMAT treatments. One important difference between SP and SMAT is the size of the spheres composing the shot. SMAT uses bigger shot then SP, a factor about ten has been used in the treatments presented in this work. The radius of shot influences the depth of the compressive residual stress layer. Indeed the thickness of compressive residual stress is deeper for SMAT treatment as expected [5]. 


\section{Conclusion}

This paper presents experimental data, whose objective is to point out at the differences between conventional shot peening and surface mechanical attrition treatment. A residual stress model is also presented to quantify the difference in the residual stress state for both treatments. Experimental evaluation of the stress field is planned.

The main advantages of SMAT are better surface quality, higher hardness, and presence of surface nanocrystalline layer. SP has the advantage of being more versatile in treating complex geometries, with shorter treatment time. SMAT is more effective than SP and is expected to further improve fatigue resistance.

\section{References}

[1] D. Retraint, C. Pilé, C. Garnier, J. Lu, 2nd edition, Society for Experimental Mechanics, vol. 1, (2005). p. 146

[2] Y. Pi, G. Agoda, S. Potiron, C. Demangel, D. Retraint, H. Benhayoune, "Surface Nanocrystallization of Ti-6Al-4VAlloy: Microstructural and Mechanical Characterization", Journal of Nanoscience and Nanotechnology, 12, (2012) pp. 4892-4897.

[2] D. Gallitelli, J. Badreddine, E. Rouhaud, M. Micoulaut, C. Labergere, M. François "From process parameters to residual stress field: complete ultrasonic shot peening simulation". 9th International conference on residual stress, Garmisch-Partenkirchen, Germany (ICRS9 2012).

[3] J. Badreddine, M. Micoulaut, E. Rouhaud, S. Remy, D. Retraint, M. François, " Effect of the confinement on the properties of ultrasonic vibrated granular gases", Granular Matter, Vol. 15 (3), pp. 367-376, 2013.

[4] J. Badreddine, D. Gallitelli, E. Rouhaud, M. Micoulaut, S. Remy, M. François, V. Desfontaine, F. Chateau, P. Renaud and G. Doubre-Baboeuf "Complete simulation of ultrasonic shot peening process". 26th International conference on surface modification technologies, Lyon, France (SMT26 2012).

[5] D. Deslaef, "Modelisation numerique du grenaillage de precontrainte : approche tridimensionnelle et dynamique" Thesis on Mechanical system and materials, Technology University of Troyes. 2000. 